\title{
Pengaruh Variasi Sudut Keluar Impeler Terhadap Performance Pompa Sentrifugal
}

\author{
Munawar Alfansury Siregar ${ }^{*}$, Wawan Septiawan Damanik ${ }^{2}$ \\ ${ }^{1,2 .}$ Fakultas Teknik Universitas Muhammadiyah Sumatera Utara \\ Email: * munawaralfansury@umsu.ac.id
}

\begin{abstract}
The ability of a pump to drain or move a certain amount of fluida / fluida that comes out through the pressure side of the pump in units of time volume is also called the capacity of a pump. Meanwhile, the pump head is the energy per unit weight that must be provided to flow the planned amount of liquid according to the pump installation conditions. A centrifugal pump is a pump that moves liquid by utilizing the centrifugal force generated by the impeller ratation. The results of data calculations and graphic analysis on the effect of variations in the impeller entry angle on the impeller with exit angle $(\beta 2)=250$,standard pump impeller, and impeller with exit angle $(\beta 2)=$ 350 on the performance of the centrifugal pump can be concluded, namely "the performance value of centrifugal pumps. The highest is the impeller with exit angle $(\beta 2)=250$ where the specific speed value produced is $192.52 \mathrm{rpm}$ and the efficiency level of this impeller is $6.82 \%$
\end{abstract}

Keywords: Impeller Angle Variation, Performance and Centrifugal Pump

\section{PENDAHULUAN}

\section{Latar Belakang}

Pompa sentrifugal adalah salah satu pompa yang umum digunakan dalam memenuhu kebutuhan yang digunakan untuk transportasi fluida, dimana kerja dari pompa tersebut tergantung dari sifat dan jenis fluida. Pemilihan jenis pompa yang digunakan didasarkan pada nilai ekonomis jarak fluida yang akan dipindahkan. Kinerja pompa sentrifugal pada dasarnya dipengaruhi oleh desain impeller dan rumah pompa[1]. Banyak faktor yang berpengaruh terhadap desain impeller seperti sudut masuk dan sudut keluar impeler serta jumlah sudu dari impeler[2]. Tujuan dari penelitian ini adalah untuk mengetahui pengaruh variasi sudut keluar impeler terhadap performance pompa sentrifugal. Pada umumnya pompa digunakan untuk menaikkan fluida dari suatu tempat yang rendah ke tempat yang lebih tinggi atau digunakan untuk mengalirkan fluida dari suatu tingkat tertentu ke suatu tempat dengan menggunakan pipa yang sangat panjang. Fluida tersebut contohnya adalah air, minyak, dan fluida lainnya yang bersifat tak mampu mampat[3].

Pada pompa akan terjadi perubahan dari energi mekanik menjadi energi fluida. Pada mesinmesin hidrolik termasuk pompa, energi fluida ini disebut head atau energi persatuan berat zat cair. Ada tiga bentuk head yang mengalami perubahan yaitu head tekan, kecepatan dan potensial. Terjadinya head pompa atau tekanan pompa semata-mata akibat putaran impeler pompa. Gaya sentrifugal yang terjadi akibat putaran impeler menyebabkan terjadinya kecepatan yang besar, yang akan diubah menjadi tekanan[4].

Performance atau daya yang diperlukan oleh pompa dapat diketahui melalui segitiga kecepatan pada sisi masuk dan pada sisi keluar sudu pompa. Pada pompa sentrifugal kecepatan fluida gerak biasa dilukiskan dalam tiga vektor yang membentuk segitiga tertutup. Pompa hadir dalam berbagai jenis untuk penggunaan yang luas. Berbagai jenis pompa tersebut antara lain ada yang menggunakan diffuser dan ada juga yang tanpa menggunakan diffuser. Diffuser berfungsi untuk mengubah arah aliran dan membantu dalam mengubah kecepatan menjadi tekanan. Pada pompa jenis diffuser, baling-baling pengarah yang tetap akan mengelilingi runner atau impeller. Laluan-laluan yang berangsur mengembang ini akan mengubah arah aliran fluida dan mengkonversikannya menjadi tinggi tekanan (pressure head). 


\section{Jurnal Rekayasa Material, Manufaktur dan Energi}

\section{Prinsip Kerja Pompa}

Pada pompa terdapat sudu-sudu impeler seperti di tunjukkan pada gambar 2.1 yang berfungsi sebagai tempat terjadi proses konversi energi dari energi mekanik putaran mejadi energi fluida head. Impeler dipasang pada poros pompa yang berhubungan dengan motor pengerak, biasanya motor listrik atau motor bakar. Poros pompa akan berputar apabila penggeraknya berputar. Karena poros pompa berputar impeler dengan sudu-sudu impeler berputar, zat cair yang ada di dalamnya akan ikut berputar sehingga tekanan dan kecepatanya naik dan terlempar dari tengah pompa ke saluran yang berbentuk volut atau spiral kemudian ke luar melalui nosel[5].

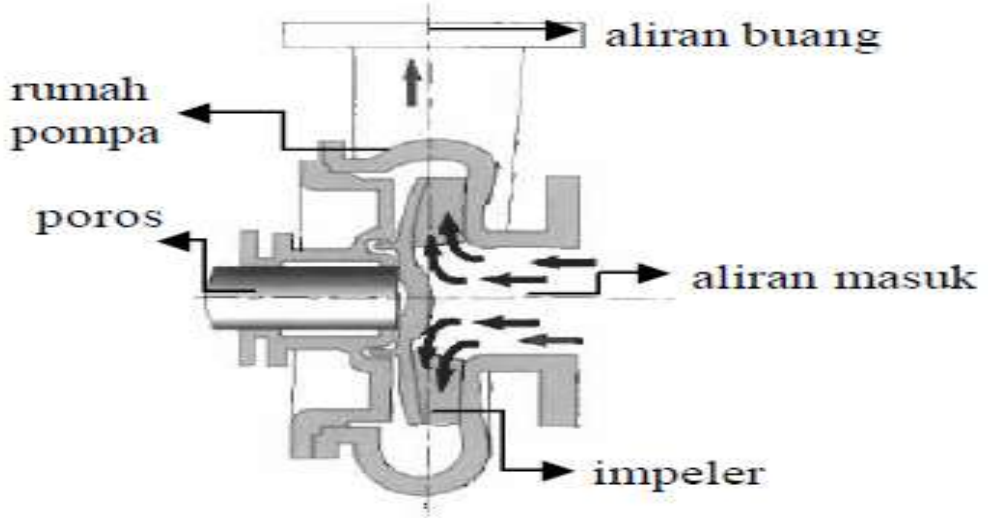

Gambar 1. Proses pemompaan

Jadi fungsi impeler pompa adalah mengubah energi mekanik yaitu putaran impeler menjadi energi fluida (zat cair). Dengan kata lain, zat cair yang masuk pompa akan mengalami pertambahan energi. Pertambahan energi pada zat cair mengakibatkan pertambahan head tekan, head kecepatan dan head potensial. Jumlah dari ketiga bentuk head tersebut dinamakan head total.

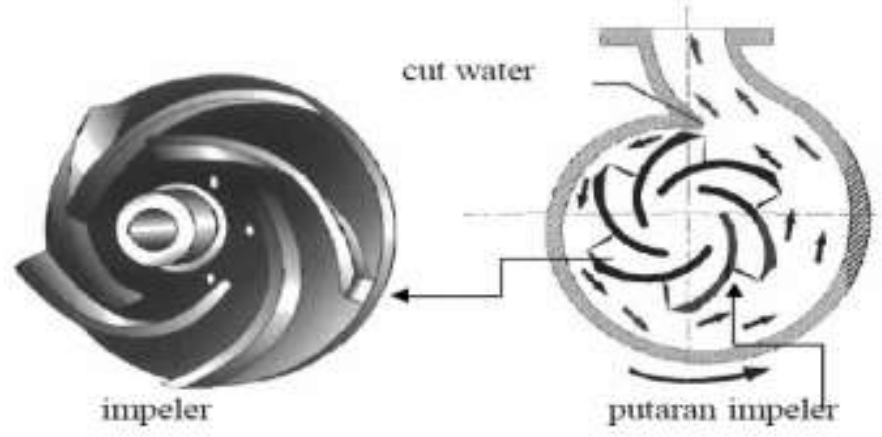

Gambar 2. Perubahan energi pada zat cair

\section{Klasifikasi Pompa}

Seperti telah dijelaskan sebelumnya, pompa adalah mesin fluida yang digunakan untuk mengalirkan fluida inkompresible (tidak mampu mampat) dari suatu tempat ke tempat lain, dari suatu tempat yang rendah ke tempat yang lebih tinggi atau dari tekanan yang rendah ke tekanan yang lebih tinggi. Dalam hal ini pembahasan pompa tidak terlepas dari pembahasan pipa hisap (suction pipe) dan pipa tekan (discharge pipe) yang secara keseluruhan juga tentang pemompaan (pumping system). 


\section{$\checkmark$ JirilRekayasa Material, Manufaktur dan Energi}

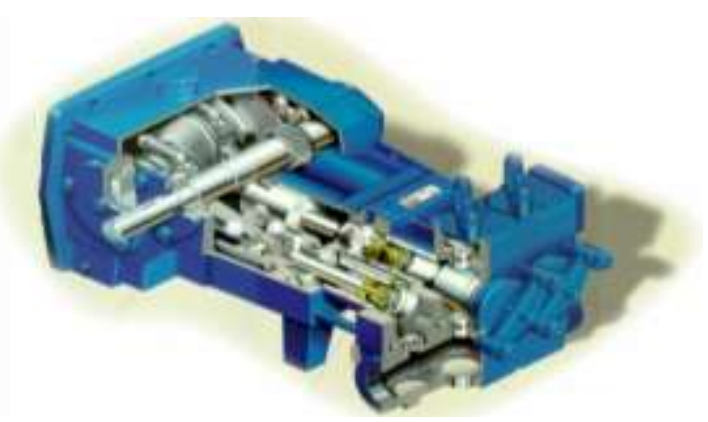

Gambar 3. Reciprocating Pump

\section{Pompa Tekanan Dinamis}

Pompa ini disebut juga dengan "Non Positive Displacement Pump", yang mana pompa tekanan dinamis terdiri dari poros, sudu-sudu impeler, volute, dan saluran keluar. Energi mekanis dari luar diberikan pada poros pompa untuk memutar impeler. Akibat putaran dari impeller menyebabkan head dari fluida menjadi lebih tinggi karena mengalami percepatan.

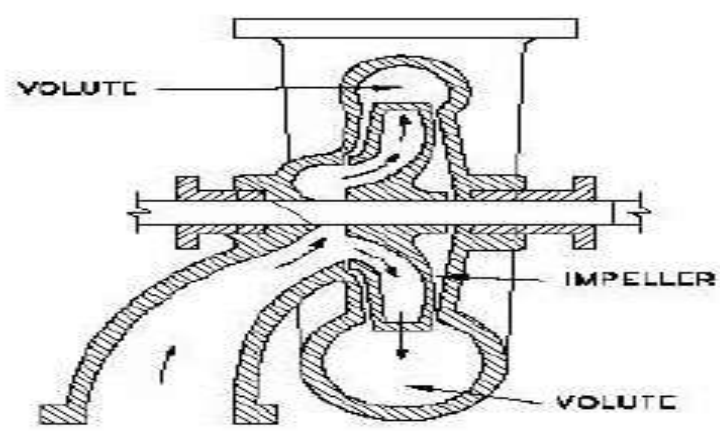

Gambar 4. Pompa aliran radial

\section{Pompa aliran aksial}

Arah aliran dalam sudu gerak pada pompa aliran aksial terletak pada bidang yang sejajar dengan sumbu poros dan head yang timbul akibat dari besarnya gaya angkat dari sudu-sudu geraknya. Pompa aliran aksial pada gambar 2.5, mempunyai head yang lebih rendah tetapi kapasitasnya lebih rendah.

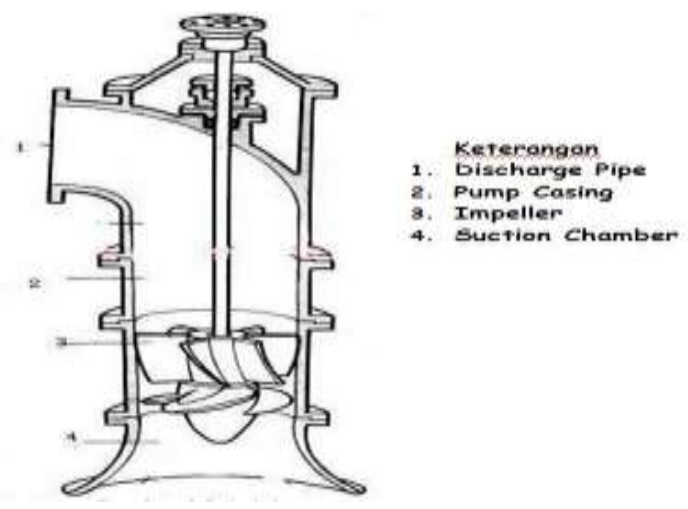

Gambar 5. Pompa aliran aksial 
Cara kerja pompa ini yaitu pertama-tama fluida cair masuk, pompa akan dijalankan oleh motor sebagai penggerak utama. Motor akan memutar poros yang akan menyebabkan sudu-sudu berputar. Lalu fluida akan dihisap oleh sudu-sudu pompa (impeler) dan menekannya ke sisi tekan dalam arah aksial.Pompa aksial biasanya diproduksi untuk memenuhi kebutuhan head rendah dengan kapasitas aliran yang besar[6].
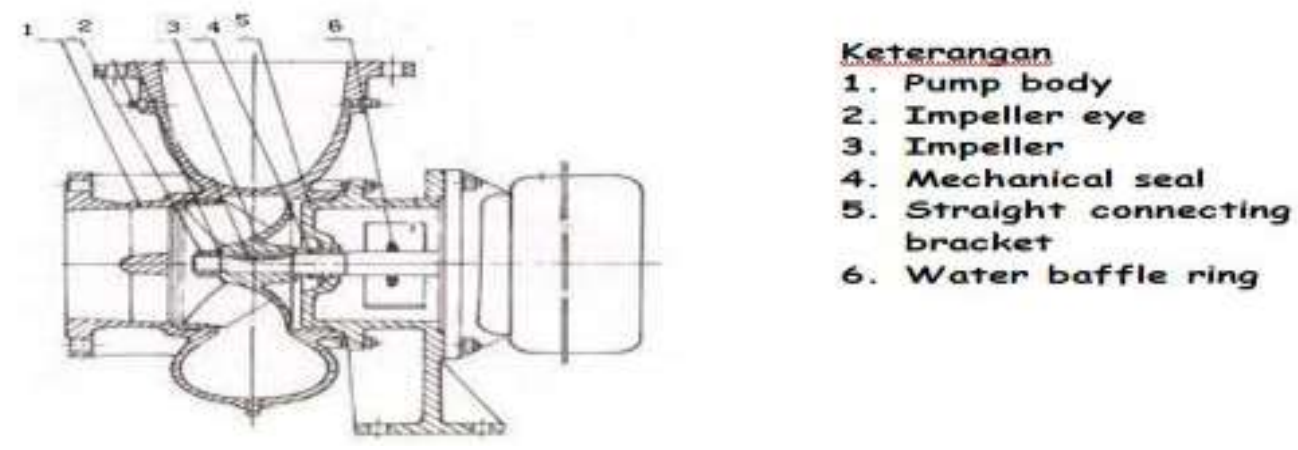

Gambar 6. Pompa aliran campur

\section{Pompa efek khusus}

Pompa efek khusus merupakan salah satu jenis pompa tekanan dinamis, dimana tekanan didalam fluida terjadi secara spesifik. Beberapa contoh pompa dari pompa jenis ini adalah pompa zet, pompa elektromagnetik, hydraulic pump, dan gas lift pump.

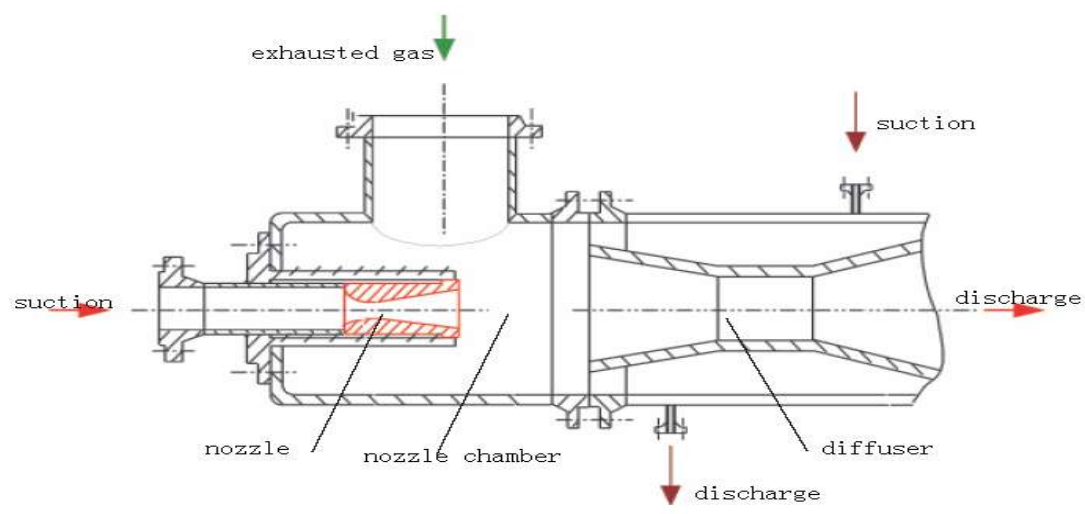

Gambar 7. Struktur pompa jet

Jadi prinsip kerja dari pompa tekanan dinamis adalah dengan mengubah energi mekanis dari poros menjadi energi fluida, dan energi inilah yang menyebabkan pertambahan head tekanan, head kecepatan, dan head potensial pada fluida yang mengalir secara kontiniu. Pada pompa tekanan dinamis terjadinya tekanan fluida akibat dari kenaikan tekanan didalam fluida, bukan dari akibat dari pergeseran volume impeler pemindahannya seperti yang terjadi ada pompa tekanan statis. Pada pompa tekanan dinamis dijumpai poros putar dengan kurungan sudu disekelilingnya dan melalui sudu-sudu inilah fluida meengalir secara kontiniu.

\section{Teori Dasar Pompa Sentrifugal}

Pompa Sentrifugal adalah pompa yang memperbesar energi fluida melalui prinsip gaya sentrifugal. Dengan diputarnya impeller atau rotor yang mempunyai sudu-sudu yang melengkung maka akan terjadi gaya sentrifugal pada butir-butir fluida yang terdapat diantara sudu-sudu, aliran 


\section{Jurnal Rekayasa Material, Manufaktur dan Energi}

fluida diarahkan oleh lengkungan sudu dan fluida akan keluar sudu dengan kecepatan yang tinggi. Fluida yang mempunyai kecepatan tinggi ini akan ditampung oleh rumah pompa atau volute yang penampangnya mulai dari kecil mengembang menjadi besar.

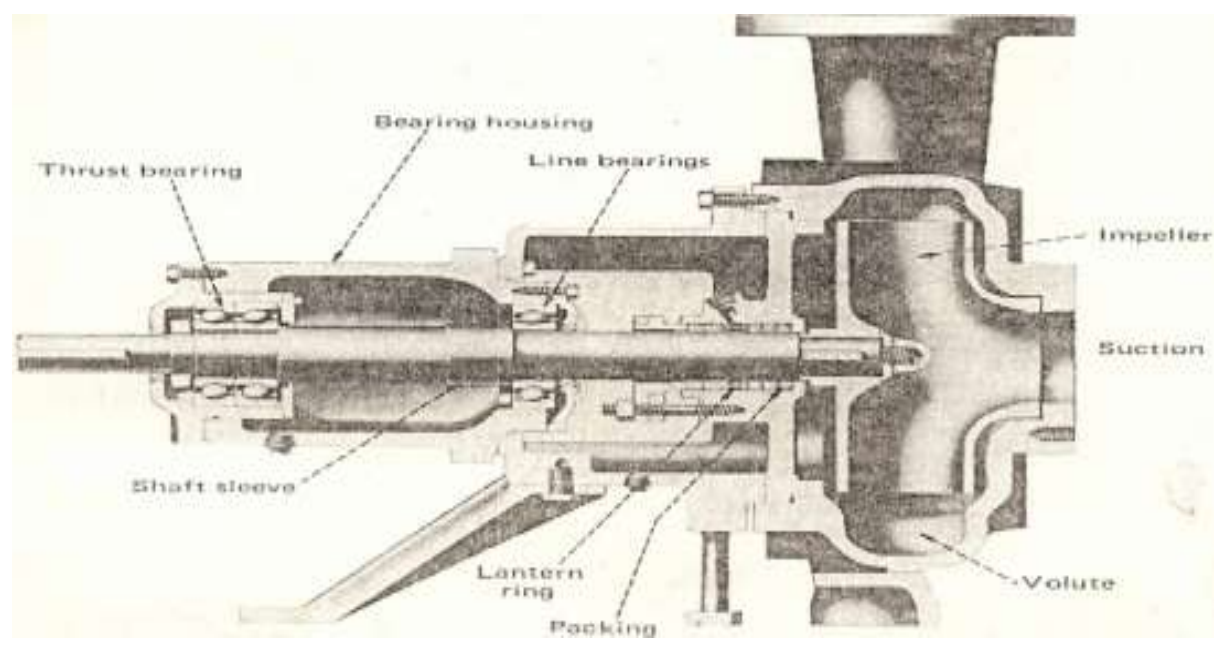

Gambar 8. Pompa sentrifugal

\section{Kerja Pompa Sentrifugal}

Pompa digerakkan oleh motor, daya dari motor diberikan kepada poros pompa untuk memutar impeler yang dipasangkan pada poros tersebut. Zat cair yang ada dalam impeler akan ikut berputar karena dorongan sudu-sudu. Karena timbulnya gaya sentrifugal, maka zat cair mengalir dari tengah impeler keluar melalui saluran diantara sudu dan meninggalkan impeler dengan kecepatan yang tinggi. Zat cair yang keluar dari impeler dengan kecepatan tinggi ini kemudian mengalir melalui saluran yang penampangnya makin membesar (volute/diffuser), sehingga terjadi perubahan dari head kecepatan menjadi head tekanan. Maka zat cair yang keluar dari flens keluar pompa head totalnya bertambah besar. Pengisapan terjadi karena setelah zat cair dilemparkan oleh impeler, ruang diantara sudu-sudu menjadi vakum sehingga zat cair akan terisap masuk.

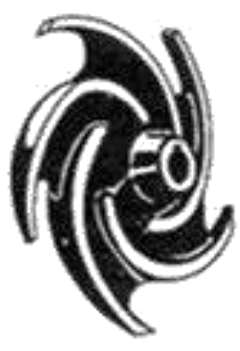

Qpen lingeler

(a)

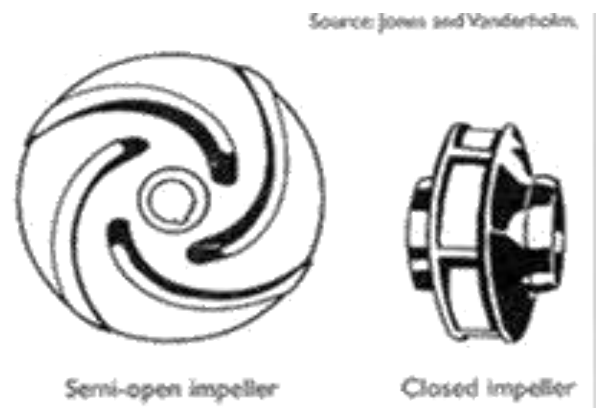

(c)

Gambar 9. Jenis impeler, (a) terbuka, (b) setengah terbuka, (c) tertutup

\section{Segitiga Kecepatan}

Fluida mengalir ke dalam pompa dikarenakan terhisap oleh impeler yang berputar, dengan menganggap bahwa aliran fluida terjadi adalah aliran dua dimensi, dan bahwa fluida mengikuti sudu-sudu impeler dengan tepat, kecepatan masuk dan keluar untuk suatu impeler yang mempunyai sudu-sudu mengarah kebelakang sebagaimana ditunjukkan dalam Gambar 10 maka, $u$ adalah

Copyright $^{\circledR} 2020$ Jurnal Rekayasa Material, Manufaktur dan Energi. This is an open acces article under the CC-BY-SA lisence (https://creativecommons.org/licenses/by-sa/4.0/). 


\section{Jurnal Rekayasa Material, Manufaktur dan Energi}

kecepatan suatu titik pada impeler relatif terhadap tanah, $w$ adalah kecepatan partikel fluida relatif terhadap impeler, dan $c$ adalah kecepatan absolut partikel fluida yang mengalir melalui impeler relatif terhadap tanah. $c$ merupakan hasil penjumlahan secara vector dari $u$ dan $w$.

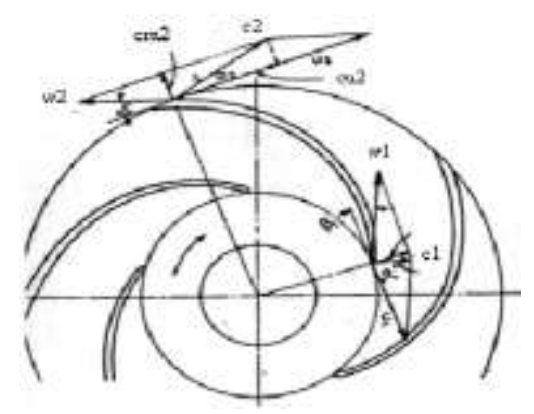

Gambar 10. Diagram kecepatan masuk dan keluar suatu impeler

Sudut antara $c$ dan $u$ disebut $\alpha$, sudut antara $w$ dan perpanjangan $u$ disebut $\beta$. Sudut $\beta$ juga merupakan sudut yang dibuat antara garis singgung terhadap sudu impeler dan suatu garis dalam arah gerakan sudu. Umumnya diagram kecepatan fluida pada impeler seperti pada Gambar 10 disederhanakan menjadi bentuk segitiga kecepatan seperti pada Gambar 11. Kecepatan relatif $w$ dan kecepatan absolute $c$ dapat diuraikan menjadi komponen kecepatan tangensial diberi subscript $u$ (searah $\mathrm{u}$ ) dan komponen kecepatan meridional dengan subscript $m$.

\section{Performance Pompa Sentrifugal}

Dalam menentukan performance pompa, salah satu variabel yang perlu dihitung adalah output daya, yang merupakan fungsi dari total dynamic head dan massa cairan yang dipompa pada rentang waktu tertentu. Jumlah kerja yang dihasilkan oleh pompa bergantung pada kapasitas dan head. Setiap pompa dirancang pada kapasitas dan head tertentu, meskipun dapat juga dioperasikan pada kapasitas dan head yang lain. Kapasitas adalah laju alir massa atau volume fluida yang dialirkan, sedangkan head adalah perbedaan total tekanan masuk dan keluar alat, yang biasanya dinyatakan dalam tinggi kolom fluida dalam kondisi adiabatik. Kurva pompa sangat penting, karena dari kurva tersebut dapat terbaca kemampuan suatu pompa disetiap titik kerja sehingga dapat ditentukan debit, total head, effisiensi, NPSHr, dan daya penggerak yang diperlukan.

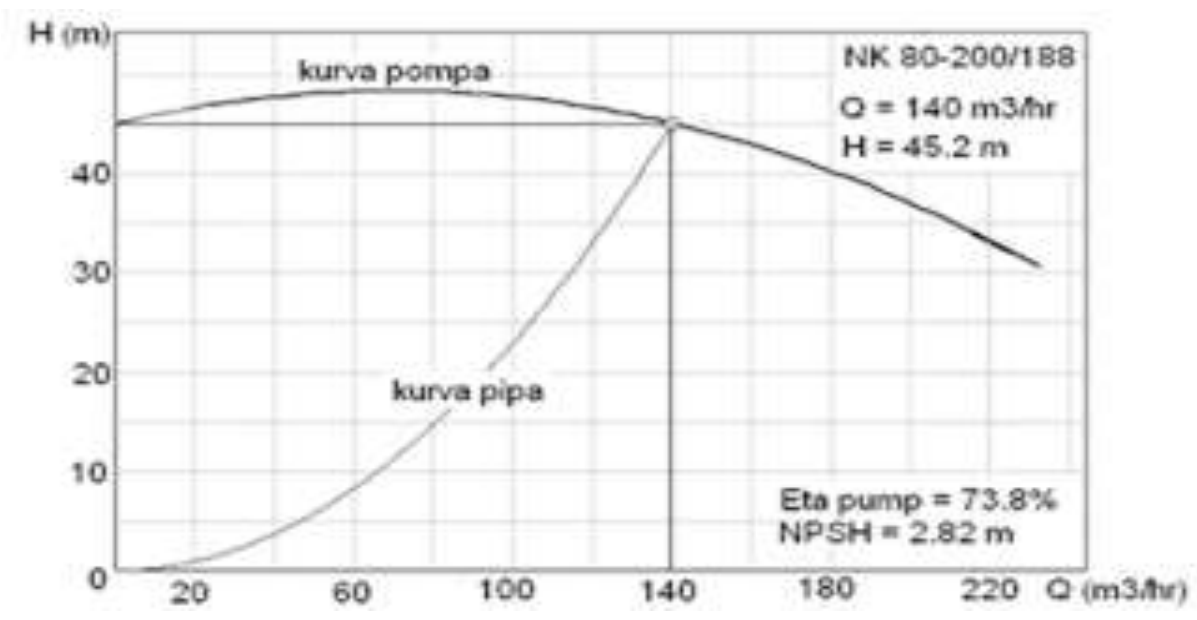

Gambar 11. Kurva karakteristik suatu pompa 


\section{Head Total Pompa}

Head total pompa adalah dengan pertambahan energi antara ujung sisi inlet dengan sisi outlet, head total juga berarti selisih head pada sisi suction dan pada sisi discharge.

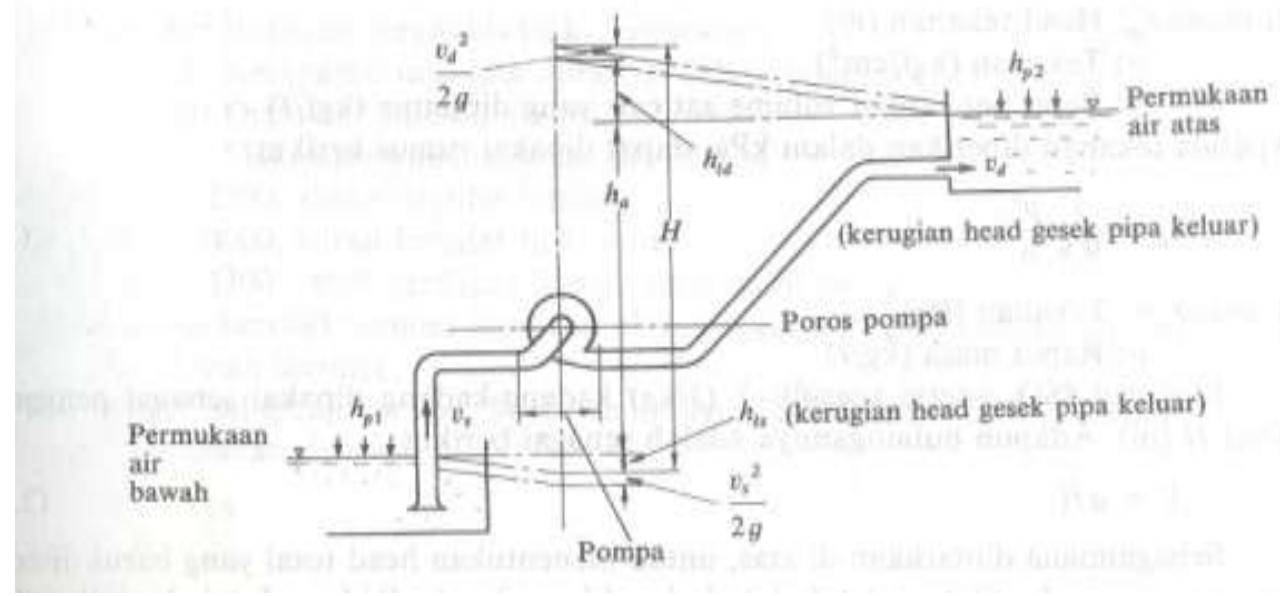

Gambar 12. Head total pompa

Head total pompa dapat ditulis dengan persamaan :

$\mathrm{H}=\mathrm{H}_{s}+\mathrm{H}_{d}$

Kecepatan spesifik didefenisikan sebagai kecepatan dalam putaran per menit, dimana suatu porsi impeler akan beroperasi secara bersamaan. Umumnya apabila diperkecil akan dapat memberikan kapasitas teruji (rating) sebesar $1 \mathrm{Gpm}$ pada tinggi tekan total sebesar $1 \mathrm{ft}$. Menurut M. Khetagurov of marini Auxiliary and System bahwa kecepatan spesifik diberi simbol (Ns) yang dinyatakan dalam rumus :

$N s=n \frac{\sqrt{Q}}{\sqrt[4]{H^{3}}}$

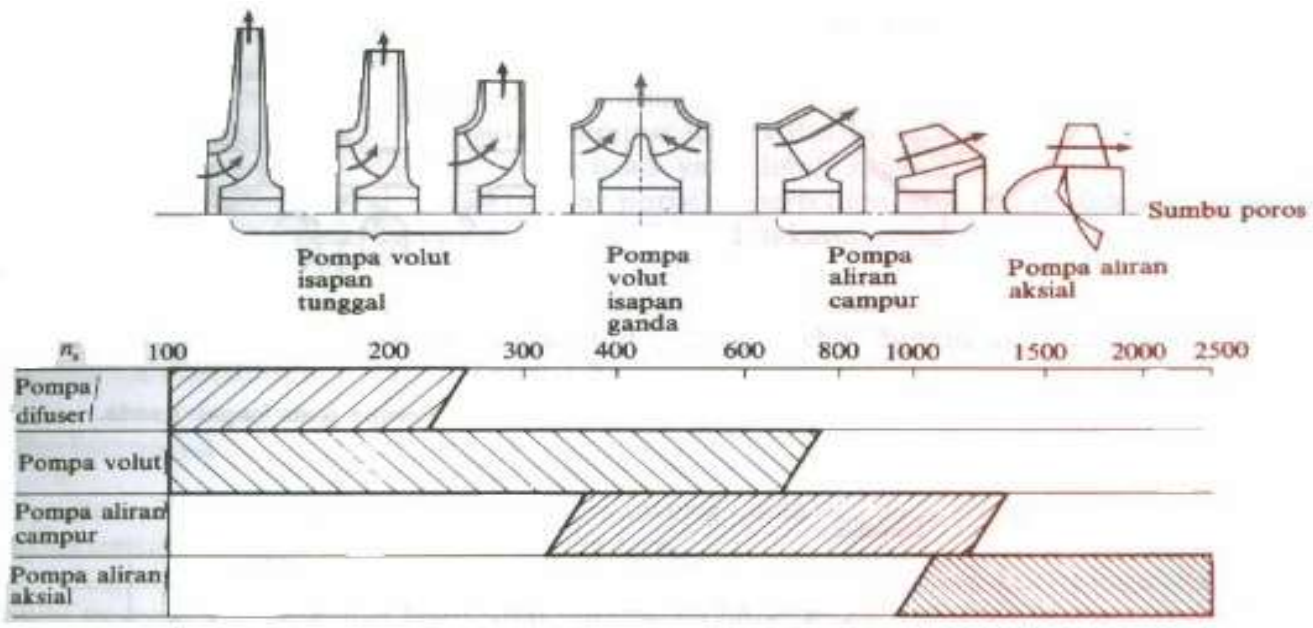

Gambar 13. Harga Ns dengan bentuk impeller dan jenis pompa

Copyright $^{\circledR} 2020$ Jurnal Rekayasa Material, Manufaktur dan Energi. This is an open acces article under the CC-BY-SA lisence (https://creativecommons.org/licenses/by-sa/4.0/). 


\section{METODE PENELITIAN}

Metode penelitian yang di gunakan adalah metode penelitian tentang performance pompa sentrifugal dengan sudut impeller yang divariasikan yaitu pada sudut keluar impeller $25^{\circ}$ dan $35^{\circ}$ sedangkan pada sudut masuknya tidak divariasikan. Impeller yang akan diuji dibuat baru dengan bahan dasar alumunium dengan proses pengecoran.

\section{HASIL DAN PEMBAHASAN}

Sistem pengujian pompa sentrifugal ini berproses memompa dari bak penampungan air kembali ke bak penampungan air. Untuk setiap impeller dilakukan pengujian sebanyak 5 kali pengujian. Pada pengujian pertama katup glove tertutup penuh, kemudian untuk pengujian kedua katup glove dibuka 25\% (1/4 bukaan), selanjutnya dibuka 50\% (1/2 bukaan), lalu 75\% (3/4 bukaan) dan pada pengujian terakhir yaitu katup glove di buka penuh. Maka diperoleh hasil data dari pengujian tersebut adalah sebagai berikut :

Tabel 1 Data hasil pengujian dengan menggunakan impeller modifikasi sudut keluar $\left(\beta_{2}\right)=25^{0}$

\begin{tabular}{ccccc}
\hline $\begin{array}{c}\text { No } \\
\text { Pengujian }\end{array}$ & Bukaan Katup Glove & $\begin{array}{c}\text { Kapasitas Q } \\
\left(\mathrm{m}^{3} / \mathrm{H}\right)\end{array}$ & $\begin{array}{c}\mathrm{P}_{\mathrm{s}} \\
(\mathrm{cm} \mathrm{Hg})\end{array}$ & $\begin{array}{c}\mathrm{P}_{\mathrm{d}} \\
\left(\mathrm{kg} / \mathrm{cm}^{2}\right)\end{array}$ \\
\hline 1 & 0 & 0 & 0 & 1,2 \\
2 & $1 / 4$ & 0,65 & $-5,5$ & 0,9 \\
3 & $1 / 2$ & 1,3 & -11 & 0,6 \\
4 & $3 / 4$ & 1,95 & $-16,5$ & 0,3 \\
5 & 1 & 2,6 & -22 & 0 \\
\hline
\end{tabular}

Keterangan dari tabel 1 yang menyatakan bahwa nilai tekanan discharge.

\section{Grafik Hasil Pengujian}

Grafik hasil pengujian impeller sudut keluar $25^{\circ}$ Adapun grafik hasil dari pengujian dengan menggunakan impeller pompa standart dan juga impeller yang dimodifikasi pada pompa sentrifugal, dapat dilihat pada grafik-grafik dibawah ini :

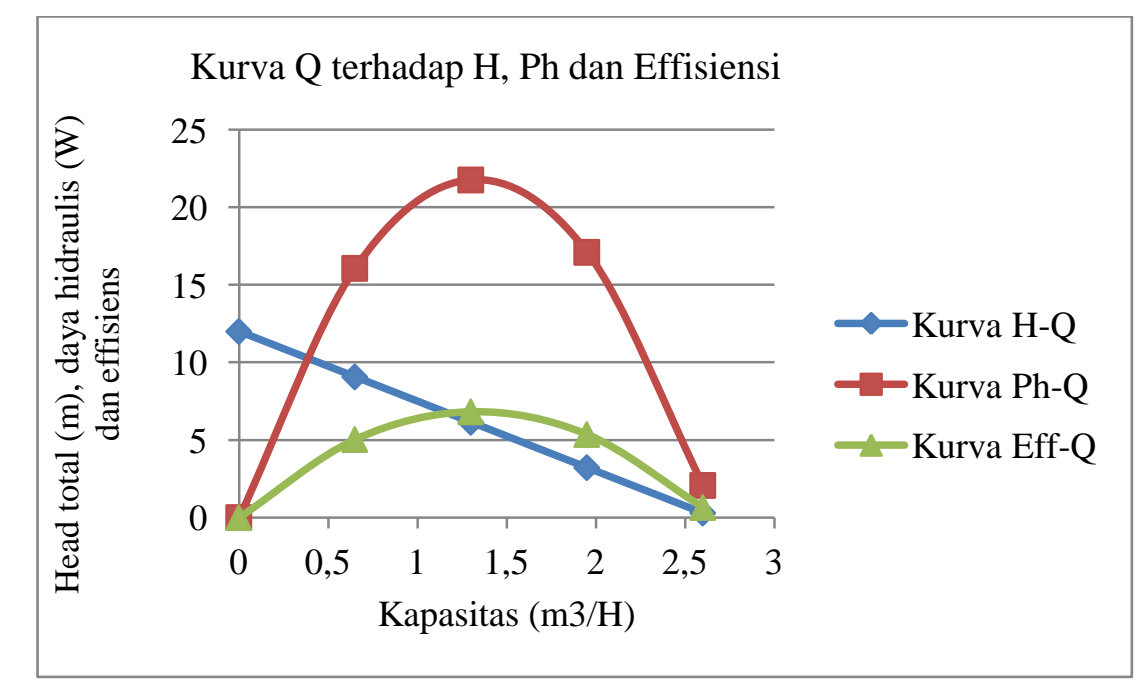

Gambar 14. Kapasitas terhadap head total, daya hidraulis dan efisiensi impeller sudut keluar $25^{\circ}$ 


\section{KESIMPULAN}

Dari data yang diperoleh setelah melakukan pengujian, kemudian hasil perhitungan data dan analisa grafik terhadap pengaruh variasi sudut masuk impeller pada impeller dengan sudut keluar $\left(\beta_{2}\right)=25^{0}$, impeller pompa standart, dan impeller dengan sudut keluar $\left(\beta_{2}\right)=35^{0}$ terhadap performance pompa sentrifugal dapat diambil kesimpulan yaitu " nilai performance pompa sentrifugal paling tinggi ialah pada impeller dengan sudut keluar $\left(\beta_{2}\right)=25^{0}$ yang mana nilai kecepatan spesifik yang dihasilkan sebesar 192,52 rpm dan tingkat efisiensi dari impeller ini yaitu $6,82 \%$. “

\section{DAFTAR PUSTAKA}

[1] Darto and I. M. Sunada, "Analisis Kinerja Geometrik Impeller Pompa Sentrifugal Berbasis Perangkat Lunak," Transm. Vol-XII Edisi-2/ Hal. 87-94 Anal., pp. 87-96, 2017.

[2] Nugroho, "Pengaruh jumlah sudu terhadap unjuk kerja dan kavitasi pompa sentrifugal," Mekanika, vol. 12, no. 2009, pp. 78-83, 2014.

[3] Mustakim, "Pengaruh Kecepatan Sudut Terhadap Efisiensi," J. Tek. Mesin Univ. Muhammadiyah Metro, vol. 4, no. 2, pp. 79-83, 2015.

[4] M. A. Siregar, K. Umurani, and W. S. Damanik, "Pengaruh Jenis Katoda Terhadap Gas Hidrogen Yang Dihasilkan Dari Proses Elektrolisis Air Garam," Media Mesin Maj. Tek. Mesin, vol. 21, no. 2, pp. 57-65, 2020, doi: 10.23917/mesin.v21i2.10386.

[5] P. Nikosai and I. S. Arief, "Optimasi Desain Impeller Pompa Sentrifugal Menggunakan Pendekatan CFD," J. Sains dan Seni ITS, vol. 4, no. 2, pp. 6-11, 2015.

[6] H. Sasongko, "Separasi Aliran Tiga Dimensi pada Kaskade Kompressor Aksial dengan Sudu Berbeda Kelengkungan," J. Tek. Mesin, vol. 10, no. 2, pp. 63-71, 2008, doi: 10.9744/jtm.10.2.pp.63-71. 